Sosvilla Rivero, S. y Manrique Simon, M. (2010) Introducción a la economía, Madrid, Garceta, 688 pp.

Los autores de este libro: SOSVILLA RIVERO y MANRIQUE SIMON, son profesores de la Universidad Complutense de Madrid, el primero es catedrático y la segunda profesora asociada de esta universidad.

Ante todo, hay que aclarar que el texto está dirigido a los alumnos de las distintas titulaciones relacionadas con la economía, si bien puede interesar también a profesores o estudiosos de esta ciencia, pero repetimos éstos no son los destinatarios directos del libro.

¿Un nuevo libro de teoría económica? Efectivamente, pero la edición de un original con este contenido no es tan frecuente como en el pasado; podríamos decir que el ámbito de esta ciencia ha quedado un poco reducido a los especialistas de la universidad. En todo caso, la publicación de un libro bien escrito y bien editado para sustituir los acostumbrados apuntes, es una buena iniciativa.

La estructura de los temas, aunque no sea totalmente original, tiene valor por sí misma; así cada capítulo comprende: un esquema del mismo, una introducción, unos apartados teóricos y ejemplos ilustrativos, un resumen, una relación de conceptos claves, unos ejercicios resueltos, otros sólo propuestos y unos ejercicios de evaluación. Los propios autores indican como pretenden que los alumnos utilicen el manual:

Lo ideal sería que los estudiantes se leyeran antes de la exposición del tema en las clases teóricas los capítulos correspondientes al tema a desarrollar, que prestaran atención a la presentación que realiza el docente... y que, después de las clases teóricas, repasaran los apuntes para ayudar a afianzar los conceptos aprendidos... (p. XVIIII).

Aunque no se indica claramente la fecha de elaboración del libro, la alusión al "proceso de Bolonia" nos demuestra que estamos ante un trabajo bastante reciente.

Si bien, se trata de un libro de teoría, con ejemplos, se incorporan algunos párrafos dedicados a la historia de las doctrinas económicas, incluso con varias fotografías de autores; esto nos parece un acierto, no muy frecuente en otros libros. Nos ha llamado la atención la poca utilización de las nuevas tecnologías, omnipresentes ya en la educación, pero suponemos que esta ausencia se tendrá en cuenta en las clases impartidas por los autores. Una pequeña crítica: la portada no responde al contenido, el lector no avisado puede pensar que estamos ante un libro sobre la crisis actual; como hemos indicado es un libro de teoría y no de temas relacionados con la actualidad.

Han cuidado especialmente la utilización del lenguaje correcto; véase, por ejemplo, la explicación lingüística de la utilización de la palabra "deflación" y no del término incorrecto, pero muy utilizado, de "deflacción".

El manual no incorpora la bibliografía habitual; evidentemente no es un olvido; los autores seguramente la han omitido dado su carácter de "introducción". Si añaden un índice analítico muy útil para el estudioso. Una cuestión muy puntual: los autores tratan de "tú" al lector; no es muy habitual, pero se explica porque se dirigen a sus alumnos. 
Comoya hemos indicado, se trata de un libro de teoría económica; a los más "antiguos" nos recuerda el conocido libro de CASTANEEDA, aunque el contenido y su estructura se diferencia sensiblemente de este último. Sin embargo, algunos apartados se refieren a aspectos relacionados con la política económica, lo que parece inevitable. Por otra parte, insistimos en que es un libro de teoría y no de economía aplicada, pero hay párrafos (por ejemplo, el 16.5 "La políica monetaria en la zona euro" y el 18.6 "Tipo de cambio en la transición hacia el euro", etc.) qué parecen más propios de un escrito de economía aplicada. Vemos, también que la distribución entre microeconomía y macroeconomía es bastante equilibrada, dedicándole aproximadamente el mismo número de páginas a cada una de ellas.

Los nombres de los capítulos nos dan una idea del contenido del manual:

0. Repaso matemático y gráfico

1. Introducción al análisis económico

\section{PARTE II: MICROECONOMÍA}

\section{Bloque I: Entorno económico}

2. Posibilidades I: Los recursos y la tecnología

3. Posibilidades II: La Frontera de Posibilidades de Producción

4. Deseos: Las preferencias del consumidor

5. Posibilidades y deseos: La elección óptima

Bloque II: El sistema de asignación competitivo

6. El sistema de asignación competitiva
7. La empresa competitiva a corto plazo

8. El consumidor competitivo

9. Los mercados de competencia perfecta

10. Elasticidad-precio de demanda

PARTE III: MACROECONOMÍA

Bloque III: Macromagnitudes

11. Conceptos macroeconómicos básicos

12. Contabilidad Nacional

Bloque IV: Modelos macroeconómicos I

13. Equilibrio general competitivo

14. Pleno empleo y paro

Bloque V: Dinero, inflación y deflación

15. El dinero

16. La inflación y la deflación

Bloque VI: Modelos macroeconómicos II

17. Oferta agregada y demanda agregada

Bloque VII: El tipo de cambio

18. El tipo de cambio

Unos breves comentarios sobre este contenido:

- Nos parece un acierto la incorporación del tema 0; aunque ciertamente, el alumno debería conocer estas nociones de matemáticas, la verdad es que a veces su ignorancia hace difícil la comprensión de los aspectos propiamente económicos.

- Echamos en falta, alguna alusión a los mercados monopolísticos $\mathrm{u}$ oligopolís- 
ticos, aunque su carácter introductorio explica esta ausencia.

- El tema de la Contabilidad Nacional parece un poco confuso.

- Los modelos macroeconómicos se refieren al modelo clásico (con pleno empleo y con paro) y al keynesiano; falta alguna alusión a teorías más recientes: monetarismo, expectativas racionales etc. Repetimos de nuevo que quizás esto se justifica en un texto de introducción a la economía. Sin embargo, la incorporación del modelo de Walras nos parece un acierto; modelo, por otra parte, que se ignora en muchos textos de economía.

- El capítulo 18 "El tipo de cambio" queda un poco aislado; un tema sobre economía internacional hubiera sido más adecuado.

Como toda obra científica, existe un cierto componente ideológico; los párrafos siguientes pueden recoger quizás la forma de pensar de los autores:

\section{Ética}

Hortal, A., Etxeberria, X. (Eds.) (2011) Profesionales y vida pública, Bilbao, Desclée de Brouwer - UNIJES (Colección Ética de las profesiones), $328 \mathrm{pp}$.

Este libro es la última publicación de la colección de Ética de las Profesiones de la Federación de Centros Universitarios de la Compañía de Jesús (UNIJES). Además
Este breve repaso a la historia del pensamiento económico revela un continuo desplazamiento del paradigma dominante desde una confianza en el poder del mercado como elemento autorregulador de desequilibrios a una creencia en la necesidad de intervención por parte del sector público para acelerar y lograr los necesarios ajustes en el mercado (p. 463).

El modelo completo para el caso keynesiano... En este modelo, una política monetaria expansiva es efectiva mientras que políticas de estímulo de la oferta de bienes y servicios resultan inefectivas y generan efectos perversos al incrementar el paro (p. 612).

Aunque nos atreveríamos a afirmar que estos párrafos representan el planteamiento ideológico de los autores, debemos indicar que estos utilizan la mayor objetividad en el desarrollo de la obra.

En resumen, un buen libro, útil para los estudiantes e interesante para los académicos.

[Adolfo Rodero FranganiLLo]

de haber publicado varios números sobre temas básicos de ética y sobre la ética general de las profesiones, ha publicado varios títulos sobre ética aplicada de diferentes grupos profesionales (enfermería, trabajo social, empresa, ayuda humanitaria, comunicación, economía, profesiones jurídicas, ingenieros, traductores e intérpretes y profesores). Con este último número se suma 